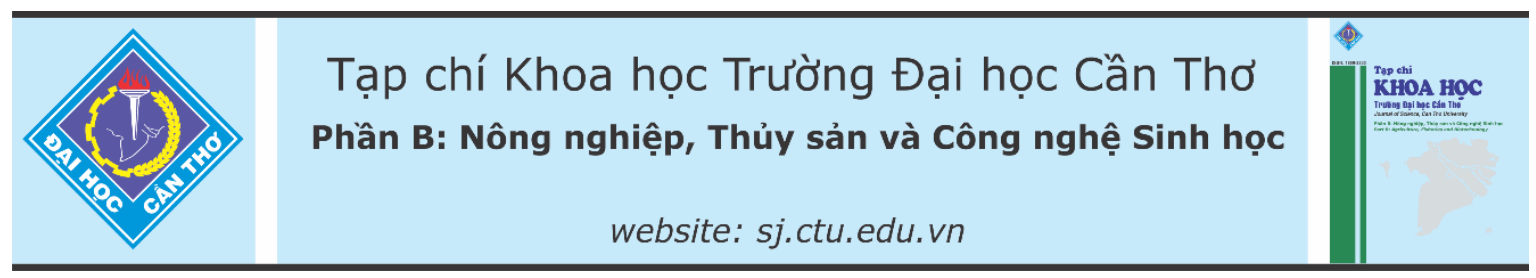

DOI:10.22144/ctu.jvn.2021.019

\title{
ẢNH HƯỞNG THỜI ĐIỂM XUỐNG GIỐNG, THỜI ĐIỂM THU HOẠCH VÀ HOẠT CHẤT SINH TRƯởNG ĐẾN NǍNG SUÂT VÀ CHẤT LƯợNG DẦ TRÓNG HẠT MÈ ĐEN (Sesamum indicum L.) TẠI TỈNH ĐỒNG THÁP
}

\author{
Trần Ngọc Hữu ${ }^{1}$, Nguyễn Hồng Huế ${ }^{1}$, Lê Vĩnh Thúc ${ }^{*}$, Lê Tuấn ${ }^{2}$ và Nguyễn Quốc Khương ${ }^{1}$ \\ ${ }^{1}$ Bộ môn Khoa học cây trồng, Khoa Nông nghiệp, Trường Đại học Cần Tho \\ ${ }^{2}$ Trung tâm Kiểm định và Kiểm nghiệm Đồng Tháp \\ *Người chịu trách nhiệm về bài viết: Lê Vinh Thúc (email: lvthuc@ ctu.edu.vn)
}

\section{Thông tin chung:}

Ngày nhận bài: 01/09/2020

Ngày nhận bài sủa: 19/10/2020

Ngày duyệt đăng: 27/02/2021

Title:

Effect of sowing time, harvesting time and plant growth promotion substances on yield and oil content in seed of sesame (Sesamum indicum L.) in Dong Thap province

\section{Tù khóa:}

Brassinolide, Canxi-Bo, mè đen, năng suất mè, thời điểm thu hoach

Keywords:

Black sesame, Brassinolide, calcium-boron, harvesting time, yield

\section{ABSTRACT}

The objective of this study was to determine the proper sowing time, plant growth promotion substances, harvest time on sesame growth and yield. The first twofactorial experiment was carried out as (A) three periods of sowing (the early 14-day sowing, farmers' concurrent sowing, and late 14-day sowing), (B) spraying of three plant growth promotion substances (Brassinolide, Calci-Bo, and Selenium). The second two-factorial experiment was carried out as (A) three periods of sowing (the early 14-day sowing, farmers' concurrent sowing, and late 14-day sowing), (B) three periods of harvest (85\%, 95\%, and 100\% yellow leaves), with three replications. The results showed that the early 14-day sowing period in comparison with farmers' sowing obtained higher number of capsules per plant, number of seeds per capsule, weight of 1,000 seeds and sesame yield. Spraying calcium - boron helped to increase number of capsules per plant in experimental site of Lap Vo whilst spraying Brassinolide supported to improve plant height, number of capsules per plant and sesame yield in Hong Ngu site. The harvest at $95 \%$ and $100 \%$ yellow leaves phases obtained higher sesame yield at $85 \%$ leaves were turning yellow. The harvest at $100 \%$ yellow leaves phase obtained higher oil content at $85 \%$ or $95 \%$ leaves were turning yellow.

\section{TÓM TẮT}

Mục tiêu của nghiên cứu là (i) xác định thòi điểm xuống giống và hoạt chất sinh truởng cho tăng năng suất mè, (ii) xác định thờ điểm thu hoạch phù hợp để đạt năng suất và hàm lượng dầu trong hạt mè. Thi nghiệm 1 được bố trí 2 nhân tố: (A) thời điểm gieo sạ (sóm 14 ngày, trùng với nông dân và trễ 14 ngày so với nông dân); (B) sử dụng hoạt chất sinh truởng (Brassinolide, Canxi-Bo và Selenium). Thi nghiệm 2 được bố trí 2 nhân tố: (A) thời điểm gieo sạ (sớm 14 ngày, trùng với nông dân và trễ 14 ngày so với nông dân), (B) thời điểm thu hoạch (85, 95 và $100 \%$ lá vàng). Mỗi nghiệm thức có 3 lần lạ̣p lại. Kết quả cho thấy xuống giống sớm 14 ngày cho số trái trên cây, số hạt trên trái, khối lượng 1.000 hạt và năng suất cao. Phun bổ sung Canxi-Bo giúp tăng số trái trên cây mè tại Lấp Vò. Trong khi phun Brassinolide làm tăng chiều cao cây, số trái trên cây và năng suất mè tại Hồng Ngụ. Thu hoạch mè vào thời điểm $95 \%$ hoạc $100 \%$ số lá chuyển vàng cho năng suất mè cao hơn so với thu hoạch mè vào thò̀ điểm $85 \%$ lá vàng. Thu hoạch mè vào thời điểm $100 \%$ số lá chuyển vàng cho hàm lương dầu trong hạt cao. 


\section{GIỚI THIỆU}

Mè là một trong những loại cây lấy dầu nổi tiếng vì dầu mè có thể được dùng làm gia vị hay làm nguyên liệu trong các ngành sản xuất khác (Langhan et al., 2008). Tại Đồng bằng sông Cửu Long (ĐBSCL) có khoảng 7.000 hectare mè, chiếm 17\% diện tích mè cả nước và mè thường được trồng luân canh trên nền đất lúa và trồng vào vụ Xuân Hè (Trần Thị Hồng Thắm, 2016). Tuy nhiên, một trong những bất lợi chính của sản xuất nông nghiệp trong vụ Xuân Hè là thiếu nước ngọt sản xuất. Một số nghiên cứu của Irmak (2017), Mousavi et al. (2011) và Rasheed (2009) cho thấy các chất điều hòa sinh trưởng như Brassinolide, hợp chất chứa Boron hay selenium có thể giúp cây trồng có thể chống chịu với điều kiện khô hạn khi sử dụng với liều lượng nhỏ. Bên cạnh đó, một số biện pháp canh tác như bố trí thời điểm xuống giống để giảm thiểu thiệt hại do thiếu nước ngọt trong sản xuất nông nghiệp cũng được nông dân lựa chọn. Ngoài ra, thời điểm thu hoạch cũng là yếu tố quyết định đến năng suất mè (Trần Thị Hồng Thắm, 2016). Tuy nhiên, hiện nay vẫn chưa có nghiên cứu cho thấy thời điểm xuống giống kết hợp với chất điều hòa sinh trưởng giúp tăng sinh trưởng, năng suất mè. Vì vậy, thí nghiệm được thực hiện nhằm mục tiêu (i) xác định thời điểm xuống giống và hoạt chất sinh trưởng phù hợp cho tăng năng suất mè, (ii) xác định thời điểm thu hoạch phù hợp để đạt năng suất và hàm lượng dầu trong hạt mè tốt nhất.

\section{PHƯƠNG TIÊN VÀ PHƯỚ PHÁP}

\subsection{Vật liệu và phương pháp nghiên cứu}

Thí nghiệm được thực hiện từ tháng 1 đến tháng 6 năm 2019 tại huyện Lấp Vò và Hồng Ngự, tỉnh Đồng Tháp.

Giống mè được sử dụng trong thí nghiệm là giống mè đen ĐH-1 có thời gian sinh trưởng ngắn (80-85 ngày), trái lớn, mỏ trái thẳng, trái có 4 múi 8 hàng hạt, được Viện khoa học kỹ thuật nông nghiệp miền Nam phục tráng từ giống mè địa phương của ĐBSCL.

Phân bón gồm: Urê $46 \% \mathrm{~N}$, DAP $(18 \% \mathrm{~N}$, $46 \% \mathrm{P}_{2} \mathrm{O}_{5}$ ), Kali Clorrua $60 \% \mathrm{~K}_{2} \mathrm{O}$.

Thí nghiệm 1 được bố trí theo kiểu khối hoàn toàn ngẫu nhiên gồm 2 nhân tố: (A) thời điểm gieo sạ (sớm 14 ngày, trùng với nông dân và trễ 14 ngày so với nông dân); $(\mathrm{B})$ sử dụng hoạt chất sinh trường (Brassinolide, Canxi-Bo và Selenium). Thí nghiệm 2 được bố trí theo kiểu khối hoàn toàn ngẫu nhiên gồm 2 nhân tố: (A) thời điểm gieo sạ (sớm 14 ngày, trùng với nông dân và trễ 14 ngày so với nông dân), (B) thời điểm thu hoạch $(85,95$ và $100 \%$ lá vàng). Mỗi nghiệm thức có 03 lần lặp lại, mỗi lặp lại có diện tích là $500 \mathrm{~m}^{2}$.

Thời điểm xuống giống sớm 14 ngày: làm đất và xuống giống ngay sau thu hoạch lúa Đông Xuân.

Trùng với nông dân: sau thu hoạch lúa Đông Xuân 07 ngày xới đất, sau 14 ngày xuống giống;

Trễ 14 ngày: sau thu hoạch lúa Đông Xuân 07 ngày xới đất, sau 28 ngày xuống giống. $\mathrm{m}^{2}$.

Mật độ gieo: lượng giống gieo là $0,4 \mathrm{~kg} / 1.000$

Bón phân cho mè theo công thức: $90 \mathrm{~N}-60 \mathrm{P}_{2} \mathrm{O}_{5^{-}}$ $60 \mathrm{~K}_{2} \mathrm{O}(19,6 \mathrm{kgUrê}-37,5 \mathrm{~kg}$ super lân - $10 \mathrm{~kg}$ kali clorua). Thời điểm và liều lượng bón như sau:

Lần 1 : bón $20 \%$ đạm và toàn bộ lân và kali thời điểm 10 ngày sau gieo (NSG). Lần 2: bón $30 \%$ đạm vào thời điểm $20 \mathrm{NSG}$. Lần 3: bón $30 \%$ đạm vào thời điểm 35 NSG. Lần 4 : bón $20 \%$ đạm vào thời điểm 45 NSG.

Hoạt chất sử dụng là Brassinolide (trích xuất từ thực vật) (1,25 ppm), Canxi-Bo (11,2 ppm Ca, 5,6 $\mathrm{ppm} \mathrm{B})$, Selenium (4 ppm) phun vào thời điểm 25 ngày và $35 \mathrm{NSG}$.

Xác định lá vàng: đếm tổng số lá và đếm số lá vàng để xác định phần trăm lá vàng.

\subsection{Phương pháp}

Các chỉ tiêu thí nghiệm được đánh giá bao gồm:

Chiều cao cây $(\mathrm{cm})$ : dùng thước dây đo từ mặt đất đến đỉnh sinh trưởng cao nhất của cây vào thời điểm 70 NSG.

Chiều cao đóng trái $(\mathrm{cm})$ : đo từ dưới gốc lên vị trí đậu trái đầu tiên của cây.

Chiều cao đoạn thân mang trái $(\mathrm{cm})$ : đo từ vị trí cho trái đầu tiên tính từ mặt đất lên đến vị trí trái cao nhất trên thân chính.

Số đốt cho trái (đốt): đếm số đốt cho trái trên cây.

Số trái trên cây (trái): đếm và ghi nhận toàn bộ trái trên cây thời điểm thu hoạch.

Số hạt trên trái (hạt): đếm tổng số hạt trên 04 trái/cây ở giữa đoạn thân mang trái.

Chiều dài trái $(\mathrm{mm})$ : đo chiều dài trái từ cuống đến đỉnh trái.

Năng suất $(\mathrm{kg} / \mathrm{ha})$ : thu năng suất hạt mè trong 30 $\mathrm{m}^{2}$ và quy ra năng suất $\mathrm{kg} / \mathrm{ha}$ ở ẩm độ $8 \%$. 
Phân tích hàm lượng lipid trong hạt mè theo phương pháp Soxhlet (Baur and Ensminger, 1977).

\subsection{Xử lý số liệu}

Số liệu được nhập và xử lý bằng phần mềm Microsoft Excel. Sử dụng phần mềm SPSS 16.0 phân tích phương sai, so sánh khác biệt trung bình giữa các nghiệm thức thí nghiệm.

\section{KẾT QUẢ VÀ THẢO LUẬN}

3.1. Ảnh hưởng của thời điểm gieo sạ, các hoạt chất Brassinolide, Canxi-Bo và Selenium đến chiều cao cây mè tại Lấp Vò và Hồng Ngự

Kết quả trình bày trong Hình 1 cho thấy chiều cao cây mè giữa các nghiệm thức khác biệt có ý nghĩa thống kê $1 \%$ tại Lấp Vò và Hồng Ngự vào thời điểm thu hoạch, cao nhất ở nghiệm thức gieo sạ trễ 14 ngày so với nông dân, đạt $114,3 \mathrm{~cm}$ và $96,3 \mathrm{~cm}$; kế đển là chiều cao cây ở thời điểm gieo trùng với nông dân $(106,7 \mathrm{~cm}$ và $77,3 \mathrm{~cm})$. Chiều cao cây thấp nhất ở thời điểm gieo sớm 14 ngày so với nông dân, chỉ $83,5 \mathrm{~cm}$ và $62,7 \mathrm{~cm}$, theo thứ tự. Như vậy, so sánh chiều cao cây ở các thời điểm gieo sạ khác nhau, thời điểm gieo trễ hơn 14 ngày so với lịch thời vụ ở địa phương cho chiều cao cây cao nhất. Kết quả này cũng tương tự với kết quả nghiên cứu của Shekh et al. (2014) về các thời điểm xuống giống mè, kết quả nghi nhận chiều cao cây tăng lên khi xuống giống trễ 21 ngày so với thời điểm xuống giống đầu tiên.

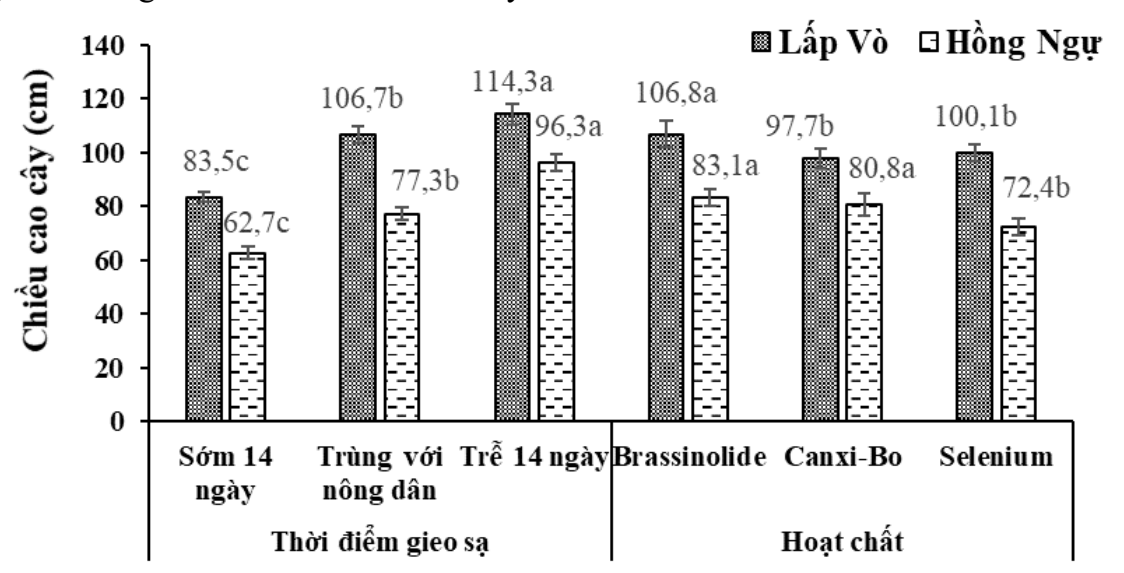

Nghiệm thức

Hình 1. Ảnh hưởng của thời điểm gieo sạ, và các hoạt chất Brassinolide, Canxi-Bo và Selenium đến chiều cao cây mè tại Lấp Vò và Hồng Ngự

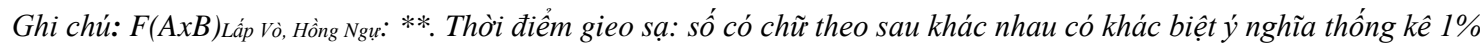
(**), hoạt chất: số có chũ theo sau khác nhau có khác biệt ý nghĩa thống kê 1\% (**). Thanh bar thể hiện sai số chuẩn

Tại Lấp Vò, chiều cao cây mè thời điểm thu hoạch khi xử lý Brassinolide có chiều cao cây cao nhất với $106,8 \mathrm{~cm}$. Chiều cao cây mè khi xử lý Canxi-Bo và Selenium lần lượt là $97,7 \mathrm{~cm}$ và 100,1 $\mathrm{cm}$, không có sự khác biệt ý nghĩa thống kê về chiều cao cây giữa hai nghiệm thức này (Hình 1 ). Tại Hồng Ngự, chiều cao cây mè thời điểm thu hoạch ở nghiệm thức phun bổ sung Brassinolide và CanxiBo có giá trị lần lượt là 83,1 và $80,8 \mathrm{~cm}$ cao hơn so với phun bổ sung Selenium $(72,4 \mathrm{~cm})$. Có sự khác biệt ý nghĩa thống kê $1 \%$ về chiều cao cây giữa các nghiệm thức (Hình 1). Theo Zullo and Adam (2002) và Vardhini (2012), sử dụng Brassinolide với nồng độ thấp thúc đẩy sinh trưởng của thực vật thông qua ảnh hưởng đến nhiều quá trình sinh lý khác nhau trong đó có điều khiển kéo dài của tế bào (Tanaka $e t$ al., 2004). Bên cạnh đó, việc bổ sung canxi cũng làm gia tăng chiều cao cây mè trồng tại Iran (Heidari $e t$ al., 2019)

3.2. Ảnh hưởng của thời điểm gieo sạ, các hoạt chất Brassinolide, Canxi-Bo và Selenium đến chiều cao đóng trái, chiều dài đoạn thân mang trái và số đốt cho trái mè tại Lấp Vò và Hồng Ngự

Chiều cao đóng trái mè, chiều dài đoạn thân mang trái và số đốt cho trái mè tại Lấp Vò giữa các thời điểm gieo sạ khác biệt có ý nghĩa thống kê $1 \%$ (Bảng 1). Trong đó, nghiệm thức xuống giống trễ 14 ngày có chiều cao đóng trái là $75,0 \mathrm{~cm}$ cao hơn nghiệm thức xuống giống sớm 14 ngày $(53,8 \mathrm{~cm})$ và nghiệm thức xuống giống trùng với nông dân $(51,1$ $\mathrm{cm})$. Trong khi đó nghiệm thức xuống giống sớm 14 
ngày có chiều dài đoạn thân mang trái và số đốt cho trái lần lượt là $45,5 \mathrm{~cm}$ và 9,9 đốt cao hơn hai nghiệm thức còn lại $27,7 \mathrm{~cm}, 8,1$ đốt; $30,5 \mathrm{~cm}$ và 7,9 đốt, theo thứ tự (Bảng 1). Nghiệm thức phun bổ sung Brassinolide có chiều cao đóng trái cao nhất $(66,0$ $\mathrm{cm})$ trong khi nghiệm thức phun bổ sung Canxi-Bo có chiều dài đoạn thân mang trái hay số đốt cho trái lớn nhất ( $38,8 \mathrm{~cm}$ và 9,8 đốt). Nghiệm thức phun bổ sung Selenium có chiều dài đoạn thân mang trái và số đốt cho trái thấp nhất lần lượt là $31,5 \mathrm{~cm}$ và 7,6 đốt (Bảng 1). Nghiên cứu trên cây lúa mì của ElFeky and Abo-Hamad (2014) chỉ ra rằng phun bổ sung Brassinolide với nồng độ $1 \mathrm{mg} / \mathrm{L}$ đã làm gia tăng sinh trưởng như chiều dài, trọng lượng tươi và trọng lượng khô của chồi và rễ.

\section{Bảng 1. Chiều cao đóng trái, chiều cao đoạn thân mang trái và số đốt cho trái mè tại Lấp Vò và Hồng Ngự}

\begin{tabular}{|c|c|c|c|c|c|}
\hline $\begin{array}{c}\text { Điá } \\
\text { điểm }\end{array}$ & Nghiệm thú & & $\begin{array}{r}\text { Chiều cao } \\
\text { đóng trái }(\mathrm{cm}) \\
\end{array}$ & $\begin{array}{r}\text { Chiều dài đoạn thân } \\
\text { mang trái }(\mathrm{cm})\end{array}$ & $\begin{array}{r}\text { Số đốt cho } \\
\text { trái (đốt) }\end{array}$ \\
\hline \multirow{6}{*}{$\begin{array}{l}\text { Lấp } \\
\text { Vò (1) }\end{array}$} & \multirow{3}{*}{$\begin{array}{l}\text { Thời điểm } \\
\text { gieo sạ }(\mathrm{A})\end{array}$} & Sớm 14 ngày & $53,8^{\mathrm{b}}$ & $45,4^{\mathrm{a}}$ & $9,9^{\mathrm{a}}$ \\
\hline & & Trùng với nông dân & $51,1^{\mathrm{b}}$ & $27,7^{\mathrm{b}}$ & $8,1^{\mathrm{b}}$ \\
\hline & & Trễ 14 ngày & $75,0^{\mathrm{a}}$ & $30,5^{\mathrm{b}}$ & $7,9^{\mathrm{b}}$ \\
\hline & \multirow{3}{*}{$\begin{array}{l}\text { Hoạt chất } \\
\text { (B) }\end{array}$} & Brassinolide & $66,0^{\mathrm{a}}$ & $33,3^{b}$ & $8,5^{\mathrm{b}}$ \\
\hline & & Canxi-Bo & $54,3^{\mathrm{c}}$ & $38,8^{\mathrm{a}}$ & $9,8^{\mathrm{a}}$ \\
\hline & & Selenium & $59,7^{\mathrm{b}}$ & $31,5^{\mathrm{b}}$ & $7,6^{\mathrm{b}}$ \\
\hline \multirow{6}{*}{$\begin{array}{l}\text { Hồng } \\
\text { Ngự } \\
\text { (2) }\end{array}$} & \multirow{3}{*}{$\begin{array}{l}\text { Thời điểm } \\
\text { gieo sạ }(\mathrm{A})\end{array}$} & Sớm 14 ngày & $44,4^{\mathrm{a}}$ & $38,4^{\mathrm{a}}$ & $8,5^{\mathrm{a}}$ \\
\hline & & Trùng với nông dân & $29,0^{\mathrm{b}}$ & $20,4^{\mathrm{b}}$ & $6,2^{\mathrm{b}}$ \\
\hline & & Trễ 14 ngày & $48,0^{\mathrm{a}}$ & $15,2^{\mathrm{c}}$ & $3,7^{\circ}$ \\
\hline & \multirow{3}{*}{$\begin{array}{l}\text { Hoạt chất } \\
\text { (B) }\end{array}$} & Brassinolide & $41,9^{\mathrm{a}}$ & $27,1^{\mathrm{a}}$ & $6,7^{\mathrm{a}}$ \\
\hline & & Canxi-Bo & $45,3^{\mathrm{a}}$ & $23,5^{\mathrm{b}}$ & $5,7^{\mathrm{b}}$ \\
\hline & & Selenium & $35,0^{\mathrm{b}}$ & $23,5^{\mathrm{b}}$ & $5,8^{\mathrm{b}}$ \\
\hline \multicolumn{3}{|l|}{$\mathrm{F}(1)(\mathrm{A})$} & $* *$ & ** & $* *$ \\
\hline \multicolumn{3}{|c|}{$\mathrm{F}(1)(\mathrm{B})$} & $* *$ & $* *$ & $* *$ \\
\hline \multicolumn{3}{|c|}{$\mathrm{F}(1)(\mathrm{AxB})$} & $* *$ & ** & $\mathrm{ns}$ \\
\hline \multicolumn{3}{|c|}{ CV (1) (\%) } & 12,5 & 22,2 & 27,5 \\
\hline \multicolumn{3}{|c|}{$\mathrm{F}(2)(\mathrm{A})$} & ** & $* *$ & ** \\
\hline \multicolumn{3}{|c|}{$\mathrm{F}(2)(\mathrm{B})$} & $* *$ & * & ** \\
\hline \multicolumn{3}{|c|}{$\mathrm{F}(2)(\mathrm{AxB})$} & ns & ns & $\mathrm{ns}$ \\
\hline \multicolumn{3}{|c|}{ CV (2) (\%) } & 19,8 & 20,5 & 19,4 \\
\hline
\end{tabular}

Ghi chú: *: khác biệt ở múc ý nghĩa 5\%, **: khác biệt ở múc ý nghĩa 1\%. ns: khác biệt không có ý nghĩa thống kê.

Bảng 2 cho thấy tại Hồng Ngự giữa các thời điểm xuống giống có chiều cao đóng trái, chiều dài đoạn thân mang trái và số đốt cho trái khác biệt ý nghĩa thống kê $1 \%$. Trong đó, nghiệm thức xuống giống sớm 14 ngày có chiều cao đóng trái, chiều dài đoạn thân mang trái và số đốt cho trái cao nhất tương ứng $44,4 \mathrm{~cm}, 38,4 \mathrm{~cm}$ và 8,5 đốt, tiếp đến là nghiệm thức xuống giống trùng với nông dân $(29,0 \mathrm{~cm} ; 20,4$ $\mathrm{cm}$ và 6,2 đốt, theo thứ tự), nghiệm thức xuống giống trễ 14 ngày có chiều cao đoạn đoạn thân mang trái và số đốt cho trái nhỏ nhất lần lượt là $15,2 \mathrm{~cm}$ và 3,7 đốt (Bảng 1 ). Kết quả tương tự cũng được tìm thấy khi nghiên cứu thời gian xuống giống mè ở Tây Nam Nigeria, khi xuống giống sớm cho thấy chiều cao cây khi ra hoa cao hơn các thời điểm xuống giống sau đó (Olowe, 2007). Giữa các nghiệm thức bổ sung hoạt chất cho thấy nghiệm thức phun bổ sung Brassinolide có chiều cao đóng trái, chiều dài đoạn thân mang trái và số đốt cho trái cao nhất $(41,9$ $\mathrm{cm} ; 27,1 \mathrm{~cm}$ và 6,7 đốt), nghiệm thức phun bổ sung
Canxi-Bo và Selenium có chiều dài đoạn thân mang trái và số đốt cho trái khác biệt không có ý nghĩa thống kê (Bảng 1).

3.3. Ảnh hưởng của thời điểm gieo sạ, các hoạt chất Brassinolide, Canxi-Bo và Selenium đến số trái trên cây mè tại Lấp Vò và Hồng Ngự

Tại Lấp Vò, số trái mè trên cây giữa các thời điểm xuống giống khác biệt có ý nghĩa thống kê $1 \%$ (Hình 2). Nghiệm thức xuống giống sớm 14 ngày có số trái trên cây cao nhất (17,2 trái/cây) tiếp đến là nghiệm thức xuống giống trùng với nông dân $(11,8$ trái/cây), nghiệm thức xuống giống trễ 14 ngày có số trái trên cây nhỏ nhất (10,3 trái/cây). Thí nghiệm tại Hồng Ngự cũng cho kết quả tương tự, nghiệm thức xuống giống sớm 14 ngày so với nông dân, xuống giống trùng với nông dân và xuống giống trê̂̃ 14 ngày có số trái trên cây lần lượt là $13,5,7,8$ và 5,9 trái/cây (Hình 2). Vì xuống giống sớm sau vụ lúa đất vẫn còn ẩm độ đây là yếu tố giúp cây mè sinh 
trưởng tốt và cho số trái trên cây cao hơn các thời điểm xuống giống sau. Kết quả này phù hợp với nhận định của Olowe (2007), khi xuống giống mè trong năm 1998 và năm 1999 tại Nigeria do năm
1998 có lượng mưa nhiều hơn nên có ẩm độ đất cao hơn và dẫn đến số trái trên cây cao hơn so với năm 1999.

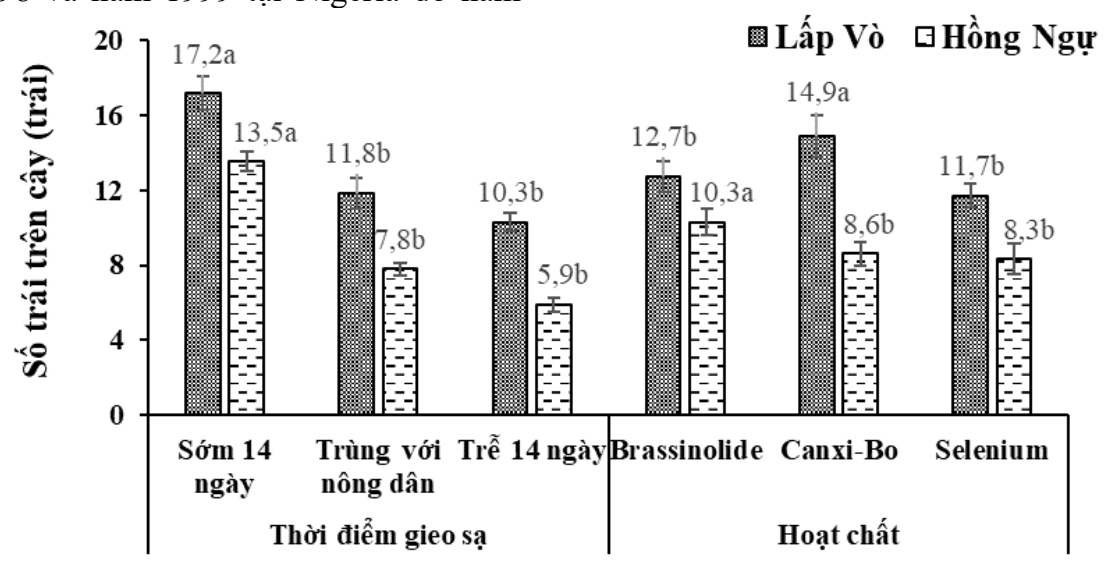

Nghiệm thức

Hình 2. Ảnh hưởng của thời điểm gieo sạ, và các hoạt chất Brassinolide, Canxi-Bo và Selenium đến số trái trên cây mè tại Lấp Vò và Hồng Ngự

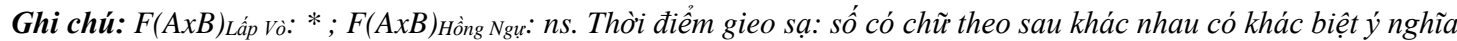
thống kê 1\% (**), hoạt chất: số có chũ theo sau khác nhau có khác biệt ý nghĩa thống kê 1\% (**). Thanh bar thể hiện sai số chuẩn

Có sự khác biệt ý nghĩa thống kê $1 \%$ giữa các thời điểm gieo sạ và các hoạt chất phun bổ sung cho mè. Cụ thể tại Lấp Vò, nghiệm thức phun bổ sung Canxi-Bo có số trái trên cây cao nhất (14,9 trái/cây), nghiệm thức phun bổ sung Brassinolide và Selenium có số trái trên cây tương đương nhau lần lượt là 12,7 và 11,7 trái/cây (Hình 2). Từ đó có thể thấy phun bổ sung Canxi-Bo giúp gia tăng số trái trên cây mè trồng ở Lấp Vò. Kết quả tương tự cũng được tìm thấy trong thí nghiệm của Heidari et al. (2019) khi phun bổ sung canxi cho mè ở nồng độ $15 \mathrm{mM}$ có số trái trên cây cao hơn so với các nồng độ thấp hơn trong điều kiện khô hạn. Tại Hồng Ngự, nghiệm thức phun bồ sung Brassinolide đã làm tăng số trái mè trên cây nhiều hơn so với phun bổ sung CanxiBo và Selenium. Số trái trên cây của ba nghiệm thức này lần lượt là 10,$3 ; 8,6$ và 8,3 trái/cây (Hình 2 ).

3.4. Ảnh hưởng của thời điểm gieo sạ, các hoạt chất Brassinolide, Canxi-Bo và Selenium đến chiều dài trái, số hạt trên trái và trọng lượng 1000 hạt mè tại Lấp Vò và Hồng Ngự

Bảng 2 cho thấy tại Lấp Vò các thời điểm gieo sạ có khác biệt ý nghĩa thống kê $1 \%$ về số hạt trên trái, chiều dài trái, trọng lượng 1.000 hạt. Trong đó, nghiệm thức có thời điểm gieo sạ sớm 14 ngày cho kết quả là 119,2 hạt/trái, chiều dài trái là 21,6 mm và khối lượng 1.000 hạt là $3,8 \mathrm{~g}$ cao hơn so với hai nghiệm thức còn lại. Nghiệm thức xuống giống trễ
14 ngày có số hạt trên trái và khối lượng 1.000 hạt thấp nhất. Kết quả này cũng tương tự với thí nghiệm của Shekh et al. (2014) xuống giống sớm giúp tăng khối lượng 1.000 hạt mè trồng tại Ấn Độ từ năm 2010 đến 2012. Chiều dài trái mè cũng được cải thiện khi phun bổ sung canxi (Heidari et al., 2019). Tại Hồng Ngự khác biệt không có ý nghĩa thống kê về số hạt trên trái, chiều dài trái và khối lượng 1.000 hạt giữa các thời điểm gieo sạ (Bảng 2). Số hạt trên trái dao động trong khoảng 99,7 đến 106,1 hạt trên trái, chiều dài trái có giá trị từ 23,8 đến $25,5 \mathrm{~mm}$ và khối lượng 1.000 hạt là 3,2 - 3,3 g (Bảng 2).

Không có sự khác biệt ý nghĩa thống kê về số hạt trên trái giữa các nghiệm thức phun bổ sung hoạt chất Brassinolide, Canxi-Bo và Selenium ở cả hai huyện Lấp Vò và Hồng Ngự (Bảng 2). Số hạt trên trái của các nghiệm thức dao động trong khoảng 101,0 đến 111,9 hạt trên trái. Phun bổ sung Brassinolide đã làm gia tăng chiều dài trái mè và khối lượng 1.000 hạt mè tại Lấp Vò so với phun bổ sung Canxi-Bo. Thí nghiệm của Bera et al. (2014) cho thấy phun bổ sung Brassinolide vào giai đoạn trổ hoa giúp gia tăng trọng lượng 1.000 hạt hoa hướng dương trồng tại Ân Độ năm 2011-2012. Trong khi tại Hồng Ngự không có sự khác biệt ý nghĩa thống kê về chiều dài trái và khối lượng 1000 hạt mè giữa các nghiệm thức phun bồ sung Brassinolide, Canxi-Bo và Selenium (Bảng 2). 
Bảng 2. Ảnh hưởng của thời điểm gieo sạ, các hoạt chất Brassinolide, Canxi-Bo và Selenium đến chiều dài trái, số hạt trên trái và trọng lượng 1.000 hạt mè tại Lấp Vò và Hồng Ngự

\begin{tabular}{|c|c|c|c|c|c|}
\hline \multirow[t]{2}{*}{$\begin{array}{l}\text { Địa } \\
\text { điểm } \\
\text { J ĥ́n }\end{array}$} & \multicolumn{2}{|c|}{ Nghiệm thức } & \multirow[t]{2}{*}{$\begin{array}{r}\text { Số } \\
\text { hạt/trái (hạt) }\end{array}$} & $\begin{array}{l}\text { Chiều dài } \\
\text { trái (mm) }\end{array}$ & $\begin{array}{r}\text { KL } \\
1.000 \text { hạt }(\mathrm{g})\end{array}$ \\
\hline & Thời điểm & Sớm 14 ngày & & $21,6^{\mathrm{a}}$ & $3,8^{\mathrm{a}}$ \\
\hline \multirow[t]{5}{*}{ Vò (1) } & gieo sạ (A) & Trùng với nông dân & $111,5^{b}$ & $17,2^{\mathrm{b}}$ & $3,8^{\mathrm{a}}$ \\
\hline & & Trễ 14 ngày & $102,4^{\mathrm{c}}$ & $21,3^{\mathrm{a}}$ & $3,4^{\mathrm{b}}$ \\
\hline & Hoạt chất & Brassinolide & 111,8 & $21,9^{\mathrm{a}}$ & $3,7^{\mathrm{a}}$ \\
\hline & (B) & Canxi-Bo & 111,9 & $16,8^{\mathrm{b}}$ & $3,6^{\mathrm{b}}$ \\
\hline & & Selenium & 109,5 & $21,2^{\mathrm{a}}$ & $3,6^{\mathrm{b}}$ \\
\hline \multirow{6}{*}{$\begin{array}{l}\text { Hồng } \\
\text { Ngự } \\
(2)\end{array}$} & Thời điểm & Sớm 14 ngày & 104,2 & 25,3 & 3,2 \\
\hline & gieo sạ (A) & Trùng với nông dân & 99,7 & 23,8 & 3,2 \\
\hline & & Trễ 14 ngày & 106,1 & 25,5 & 3,3 \\
\hline & Hoạt chất & Brassinolide & 103,8 & 24,7 & 3,2 \\
\hline & (B) & Canxi-Bo & 105,2 & 24,8 & 3,3 \\
\hline & & Selenium & 101,0 & 25,1 & 3,2 \\
\hline \multicolumn{3}{|c|}{$\mathrm{F}(1)(\mathrm{A})$} & $* *$ & $* *$ & $* *$ \\
\hline \multicolumn{3}{|c|}{$\mathrm{F}(1)(\mathrm{B})$} & $\mathrm{ns}$ & ** & $* *$ \\
\hline \multicolumn{3}{|c|}{$\mathrm{F}(1)(\mathrm{AxB})$} & $\mathrm{ns}$ & $* *$ & * \\
\hline \multicolumn{3}{|c|}{ CV (1) (\%) } & 12,6 & 11,5 & 4,0 \\
\hline \multicolumn{3}{|c|}{$\mathrm{F}(2)(\mathrm{A})$} & ns & $\mathrm{ns}$ & ns \\
\hline \multicolumn{3}{|c|}{$\mathrm{F}(2)(\mathrm{B})$} & ns & $\mathrm{ns}$ & ns \\
\hline \multicolumn{3}{|c|}{$\mathrm{F}(2)(\mathrm{AxB})$} & $\mathrm{ns}$ & $\mathrm{ns}$ & $\mathrm{ns}$ \\
\hline \multicolumn{3}{|c|}{$\mathrm{CV}(2)(\%)$} & 13,5 & 13,3 & 4,7 \\
\hline
\end{tabular}

Ghi chú: *: khác biệt ở múc ý nghĩa 5\%, **: khác biệt ở mức ý nghĩa 1\%. Các số trong cùng cột có chũ theo sau giống nhau không biệt ý nghĩa thống kê. KL: khối lương

3.5. Ảnh hưởng của thời điểm gieo sạ, các hoạt chất Brassinolide, Canxi-Bo và Selenium đến năng suất mè tại Lấp Vò và Hồng Ngự

Kết quả trình bày trong Hình 3 cho thấy năng suất mè tại Lấp Vò và Hồng Ngự cao nhất ở nghiệm thức xuống giống sớm 14 ngày so với nông dân, đạt 829,1 và $794,2 \mathrm{~kg} / \mathrm{ha}$, kế đến là nghiệm thức xuống giống trùng với nông dân $(727,3$ và $623,9 \mathrm{~kg} / \mathrm{ha})$. Sau cùng, thấp nhất là năng suất ở thời điểm xuống giống trễ 14 ngày so với nông dân chỉ với 702,4 và $600,0 \mathrm{~kg} / \mathrm{ha}$, theo thứ tự. Giữa các nghiệm thức khác biệt có ý nghĩa thống kê 1\% (Hình 3). Như vậy, trong thí nghiệm so sánh năng suất ở các thời điểm gieo sạ khác nhau, thời điểm xuống giống sớm hơn 14 ngày so với nông dân cho năng suất cao nhất. Điều này có thể giải thích vì canh tác mè vụ Xuân Hè thường thiếu nước tưới nên việc xuống giống sau khi kết thúc vụ lúa càng lâu sẽ làm giảm lượng nước trong đất từ đó giảm năng suất mè. Theo Myint $e t$ al., (2019) trồng mè vào thời điểm mùa mưa ngắn nghĩa là lượng nước cung cấp cho mè ít, dẫn đến làm giảm năng suất mè. Tuy nhiên, lượng mưa nhiều cũng là nguyên giảm số lượng và chất lượng mè
(Myint et al., 2020). Ngoài ra, điều kiện môi trường và mùa vụ cũng ảnh hưởng đến kiểu gen từ đó ảnh hưởng đến năng suất mè (Okello-Anyanga et al., 2016). Nghiên cứu về thời gian gieo sạ của Ogbonna and Umar-Shaba (2012) cho thấy gieo sạ sớm làm tăng năng suất mè tại Đông Nam Nigeria và gieo sạ trễ làm giảm năng suất mè từ 42 đến $91 \%$.

Tại Lấp Vò giữa ba nghiệm thức phun bổ sung hoạt chất Brassinolide, Canxi-Bo và Selenium khác biệt không có ý nghĩa thống kê về năng suất (Hình 3). Trong đó, năng suất mè giữa ba nghiệm thức này dao động trong khoảng 715,0 - 779,9 kg/ha. Tại Hồng Ngự, nghiệm thức phun bổ sung Selenium cho năng suất là $616,2 \mathrm{~kg} / \mathrm{ha}$ khác biệt thống kê ở mức ý nghĩa $1 \%$ so với phun bổ sung Brassinolide và Canxi-Bo (Hình 3). Nghiệm thức phun bổ sung Canxi-Bo có năng suất $665,6 \mathrm{~kg} / \mathrm{ha}$ khác biệt không có ý nghĩa thống kê so với nghiệm thức phun bổ sung Brassinolide $(689,4 \mathrm{~kg} / \mathrm{ha})$ Theo Heidari et al. (2019), phun bổ sung canxi giúp cải thiện sinh trưởng, quang hợp, giúp hấp thu dinh dưỡng tốt, dẫn đến tăng năng suất hạt. 


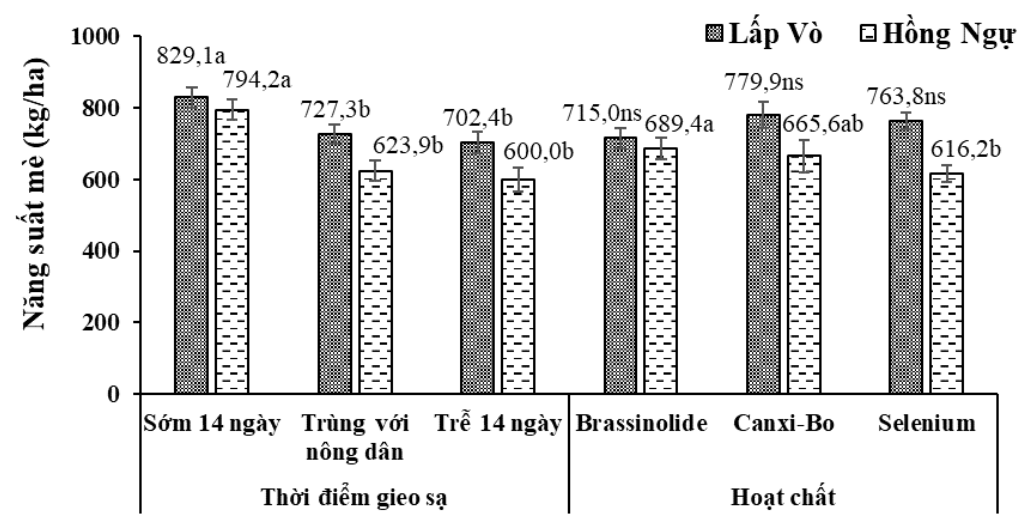

Nghiệm thức

Hình 3. Ảnh hưởng của thời điểm gieo sạ, và các hoạt chất Brassinolide, Canxi-Bo và Selenium đến năng suất mè tại Lấp Vò và Hồng Ngự

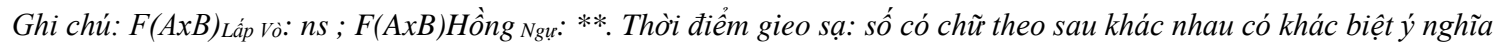
thống kê 1\% (**), hoạt chất: số có chũ theo sau khác nhau có khác biệt ý nghĩa thống kê 1\% (**). Thanh bar thể hiện sai số chuẩn

3.6. Ảnh hưởng của thời điểm thời điểm gieo sạ và thu hoạch đến năng suất mè tại Lấp Vò và Hồng Ngự

Tại Lấp Vò, năng suất mè giữa các thời điểm thu hoạch có khác biệt ý nghĩa thống kê $1 \%$ (Hình 4). Thu hoạch vào thời điểm trên cây có $100 \%$ và $95 \%$ số lá vàng cho năng suất cao nhất, lần lượt là 789,3 và $774,2 \mathrm{~kg} / \mathrm{ha}$. Thu hoạch vào thời điểm trên cây có $85 \%$ số lá vàng cho năng suất thấp nhất $(695,2$ $\mathrm{kg} / \mathrm{ha}$ ). Tại Hồng Ngự, giữa các thời điểm thu hoạch $85 \%, 95 \%$ và $100 \%$ số lá vàng đạt năng suất khác biệt có ý nghĩa thống kê $5 \%$. Đối với thu hoạch vào thời điểm cây có $95 \%$ số lá chuyển sang màu vàng cho thấy năng suất $(699,2$ kg/ha) lớn hơn so với hai thời điểm còn lại (Hình 4), tuy nhiên, không có sự khác biệt ý nghĩa thống kê giữa thu hoạch thời điểm $95 \%$ số lá vàng và $100 \%$ số lá vàng (Hình 4$)$. Kết quả nghiên cứu cho thấy thu hoạch sớm tại thời điểm trái chưa chín năng suất sẽ giảm 15\% (Langham, 2008), thu hoạch trễ khi trái quá chín trái sẽ tự nứt và hạt rơi xuống đất cũng làm giảm năng suất hạt (Trần Thị Hồng Thắm, 2016). Kết quả tương tự cũng được ghi nhận bởi Sarkar et al. (2007), thu hoạch vào thời điểm 40 và 45 ngày sau trổ hoa sẽ cho năng suất cao hơn thu hoạch vào thời điểm 30 và 35 ngày sau trổ hoa. Do đó, thu hoạch mè vào thời điểm có $95 \%$ và $100 \%$ số lá chuyển sang màu vàng sẽ cho năng suất tối ưu.

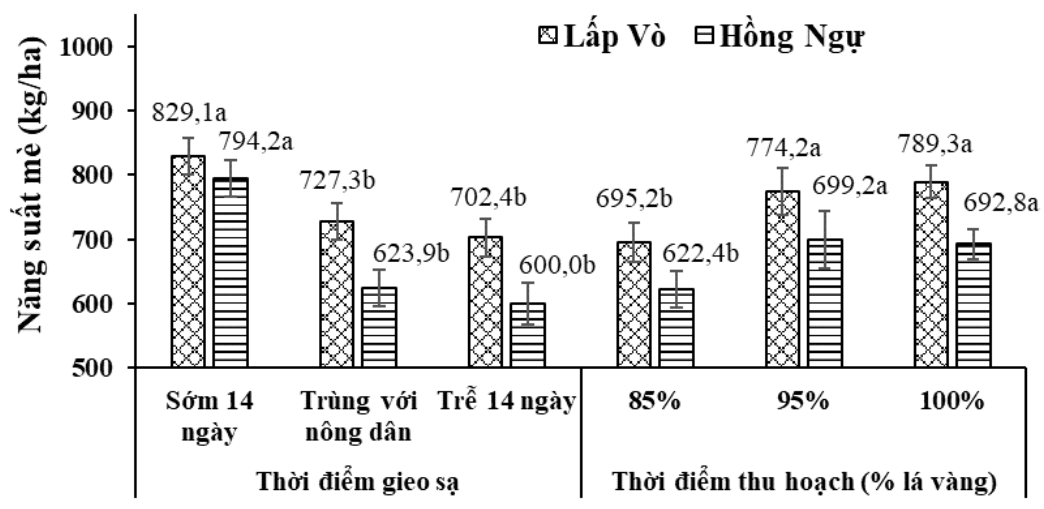

Nghiệm thức

Hình 4. Ảnh hưởng của thời điểm thời điểm gieo sạ và thu hoạch đến năng suất mè tại Lấp Vò và Hồng Ngự

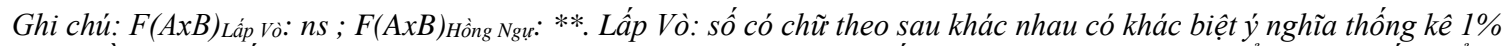
(**). Hồng Ngụ: số có chũ theo sau khác nhau có khác biệt ý nghĩa thống kê 5\% (*). Thanh bar thể hiện sai số chuẩn 


\section{7. Ảnh hưởng của thời điểm thời điểm gieo sạ và thu hoạch đến hàm lượng dầu trong hạt mè tại Lấp Vò và Hồng Ngự}

Tại Lấp Vò, hàm lượng dầu trong hạt mè cao nhất ở nghiệm thức xuống giống trễ 14 ngày $(47,7 \%)$. Giữa hai nghiệm thức xuống giống sớm 14 ngày và xuống giống trùng với nông dân có hàm lượng dầu trong hạt mè tương đương nhau, lần lượt là 44,9 và $46,2 \%$. Giữa ba thời điểm gieo sạ có khác biệt ý nghĩa thống kê $1 \%$ về hàm lượng dầu trong hạt mè (Hình 5). Tuy nhiên, không có sự khác biệt ý nghĩa thống kê về hàm lượng dầu trong hạt mè giữa các thời điểm xuống giống tại Hồng Ngự (Hình 5). Thu hoạch vào thời điểm $100 \%$ số lá trên cây ngả vàng cho hàm lượng dầu trong hạt mè cao nhất ở cả hai huyện Lấp Vò và Hồng Ngự (48,9 và $50,2 \%)$. Thu hoạch vào thời điểm $95 \%$ số lá trên cây ngả vàng cho hàm lượng dầu trong hạt mè thấp hơn $(45,7$ và $45,8 \%$ ), thu hoạch vào thời điểm $85 \%$ số lá trên cây ngả vàng cho hàm lượng dầu trong hạt mè thấp nhất $(44,1$ và $45,1 \%)$ (Hình 5$)$. Kết quả nghiên cứu này tương tự của De la Vega and Hall (2002) thời gian xuống giống ảnh hưởng đến hàm lượng dầu trong hạt hướng dương. Tuy nhiên, chưa có sự khác biệt về hàm lượng dầu trong hạt của cây dược liệu khi xuống giống từ tháng 11 năm trước đến tháng 2 năm sau (Soleimani et al., 2011). Kết quả xác định hàm lượng dầu trong hạt mè cũng phù hợp với nghiên cứu trước đây, mè có hàm lượng dầu trong hạt khoảng $44-57 \%$ (Sharaby and Butovchenko, 2019). Thí nghiệm về thời gian thu hoạch và hàm lượng dầu trong hạt của cây thuộc họ bầu cho thấy thu hoạch ở thời điểm 50 ngày sau khi đậu trái cho hàm lượng dầu tốt hơn so với thu hoạch vào thời điểm 30 ngày sau đậu trái (Loukou et al., 2011).

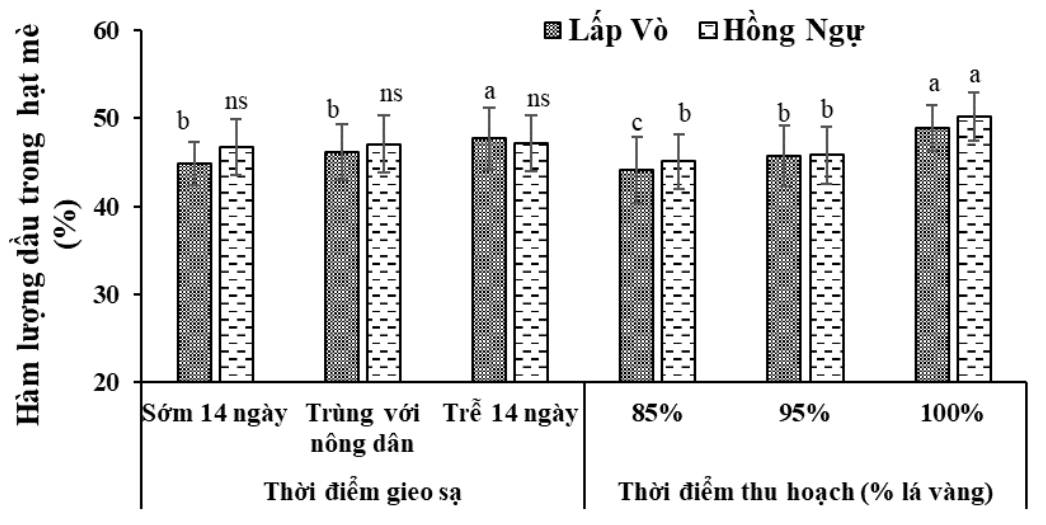

Nghiệm thức

Hình 5. Ảnh hưởng của thời điểm thời điểm gieo sạ và thu hoạch đến hàm lượng dầu trong hạt mè tại Lấp Vò và Hồng Ngự

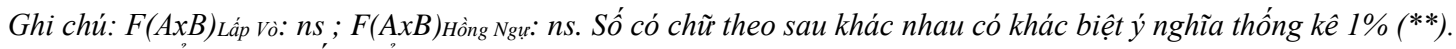

Thanh bar thể hiện sai số chuẩn

\section{KÊT LUẬN}

Xuống giống sớm 14 ngày cho chiều dài đoạn thân mang trái, số đốt cho trái, số trái trên cây, số hạt trên trái, và khối lượng 1.000 hạt và năng suất cao hơn so với xuống giống cùng thời điểm với nông dân hay trễ hơn 14 ngày.

Phun bổ sung Canxi-Bo giúp tăng chiều dài đoạn thân mang trái, số đốt cho trái và số trái trên cây mè tại Lấp Vò trong khi phun bổ sung Brassinolide giúp tăng chiều cao cây, chiều dài đoạn thân mang trái, số đốt cho trái, số trái trên cây và năng suất mè tại Hồng Ngự.

Thu hoạch mè vào thời điểm $95 \%$ hoặc $100 \%$ số lá chuyển sang màu vàng cho năng suất mè cao hơn so với thu hoạch mè vào thời điểm $85 \%$ lá vàng. Thu hoạch mè vào thời điểm $100 \%$ số lá chuyển sang màu vàng cho hàm lượng dầu trong hạt cao hơn so với thu hoạch vào thời điểm cây có $85 \%$ hay $95 \%$ số lá chuyển sang màu vàng.

\section{LỜI CẢM ON}

Nhóm tác giả xin chân thành cám ơn Sở Khoa học và Công nghệ tỉnh Đồng Tháp đã hỗ trợ kinh phí nghiên cứu thông qua dự án "Ứng dụng tiến bộ kỹ thuật xây dựng mô hình sản xuất mè luân canh trên nền đất lúa gắn với tiêu thụ tại tỉnh Đồng Tháp" thời gian thực hiện từ tháng 3/2019 đến tháng 3/2021.

\section{TÀI LIỆU THAM KHẢO}

Baur, F. J., \& Ensminger, L. G. (1977). The association of official analytical chemists 
(AOAC). Journal of the American Oil Chemists' Society, 54(4), 171-172.

Bera, A. K., Pramanik, K., \& Mandal, B. (2014). Response of biofertilizers and homo-brassinolide on growth, yield and oil content of sunflower (Helianthus annuus L.). African Journal of Agricultural Research, 9(48), 3494-3503.

De la Vega, A. J., \& Hall, A. J. (2002). Effects of Planting Date, Genotype, and Their Interactions on Sunflower Yield: I. Determinants of OilCorrected Grain Yield. Crop Science, 42(4), 1191-1201.

El-Feky, S. S., \& Abo-Hamad, S. A. (2014). Effect of exogenous application of Brassinolide on growth and metabolic activity of wheat seedlings under normal and salt stress conditions. Annual Research \& Review in Biology, 3687-3698.

Heidari, M., Amirfazli, N., Ghorbani, H., \& Zafarian, F. (2019). Calcium Chloride and Drought Stress Changed Grain Yield and Physiological Traits in Sesame (Sesamum indicum L.). Scientia agriculturae bohemica, 50(4), 211-218.

Irmak, S. (2017). Effects of Selenium Application on Plant Growth and Some Quality Parameters in Peanut (Arachis hypogaea). Pakistan journal of biological sciences, Vol 20, 92-99.

Langham, D. R. (2008). Growth and development of sesame. Sesaco Corp, 329 pages.

Loukou, A. L., Lognay, G., Barthelemy, J. P., Maesen, P., Baudoin, J. P., \& Zoro, B. I. A. (2011). Effect of harvest time on seed oil and protein contents and compositions in the oleaginous gourd Lagenaria siceraria (Molina) Standl. Journal of the Science of Food and Agriculture, 91(11), 2073-2080.

Mousavi, S. R., Shahsavari, M., \& Rezaei, M. (2011). A general overview on manganese (Mn) importance for crops production. Australian Journal of Basic and Applied Sciences, 5(9), 1799-1803.

Myint, D., Gilani, S. A., Kawase, M., \& Watanabe, K. N. (2020). Sustainable Sesame (Sesamum indicum L.) Production through Improved Technology: An Overview of Production, Challenges, and Opportunities in Myanmar. Sustainability, 12(9), 3515, 21 pages.

Myint, T., \& Kyaw, E. M. T. (2019). Assessment of Supply Chain Management of Sesame Seed in Pakokku Township, Magway Region, Myanmar. International Journal, 6(2), 215-224..

Ogbonna, P. E., \& Umar-Shaba, Y. G. (2012). Time of sowing affects the growth and yield of sesame in a derived Savanna agroecology of southeastern Nigeria. The Philippine Agricultural Scientist, 95(2), 153-159.

Okello-Anyanga, W., Rubaihayo, P., Gibson, P., \& Okori, P. (2016). Genotype by environment interaction in sesame (Sesamum indicum $\mathrm{L}$.) cultivars in Uganda. African Journal of Plant Science, 10(10), 189-202.

Olowe, V. I. O. (2007). Optimum planting date for sesame (Sesamum indicum L.) in the transition zone of south west Nigeria. Agricultura tropica et subtropica, 40(4), 156-164.

Rasheed, M. K. (2009). Role of boron in plant growth: a review. J Agric Res, 47(3).

Sarkar, M. A., Salim, M., Islam, N., \& Rahman, M. M. (2007). Effect of sowing date and time of harvesting on the yield and yield contributing characters of sesame (Sesamum indicum L.) seed. International Journal of Sustainable Crop Production, 2(6), 31-35.

Sharaby, N., \& Butovchenko, A. (2019). Cultivation technology of sesame seeds and its production in the world and in Egypt. In IOP Conference Series: Earth and Environmental Science (Vol. 403, No. 1, p. 012093). IOP Publishing, 8 pages.

Shekh, M. A., Mathukia, R. K., \& Sagarka, B. K. (2014). Sowing time and spacing for Summer Sesame (Sesamum indicum L.). Agriculture: Towards a New Paradigm of Sustainability, 111-115.

Soleimani, B., Khosh-Khui, M., \& Ramezani, S. (2011). Planting date effects on growth, seed yield, essential oil content and chemical composition of Ajowan. Journal of Applied Biological Sciences, 5(3), 7-11.

Tanaka, K., Nakamura, Y., Asami, T., Yoshida, S., Matsuo, T., \& Okamoto, S. (2003). Physiological roles of brassinosteroids in early growth of Arabidopsis: brassinosteroids have a synergistic relationship with gibberellin as well as auxin in light-grown hypocotyl elongation. Journal of Plant Growth Regulation, 22(3), 259-271.

Trần Thị Hồng Thắm, (2016). Nghiên cứu phát triển cây vừng trong hệ thống canh tác có lúa vùng đất xám Đồng Tháp Mười. Hội thảo Quốc gia về Khoa học Cây trồng lần thứ hai, ngày 1112/8/2016, Cần Thơ. Nhà xuất bản Viện Khoa học Nông nghiệp Việt Nam. Hà Nội, 722-728.

Vardhini, B. V. (2012). Effect of Brassinolide on certain enzymes of sorghum grown in saline soils of Karaikal. Journal of Phytology, 4(2): 30-33.

Zullo, M. A. T., \& Adam, G. (2002). Brassinosteroid phytohormones: structure, bioactivity and applications. Brazilian Journal of Plant Physiology, 14(3), 143-181. 